\title{
Energetics and longevity in birds
}

\author{
L. J. Furness • J. R. Speakman
}

Received: 8 April 2008 / Accepted: 14 April 2008 /Published online: 25 June 2008

(C) American Aging Association 2008

\begin{abstract}
The links between energy expenditure and ageing are different at different levels of enquiry. When studies have examined the relationships between different species within a given class the association is generally negative - animals with greater metabolism per gram of tissue live shorter lives. Within species, or between classes (e.g. between birds and mammals) the association is the opposite - animals with higher metabolic rates live longer. We have previously shown in mammals that the negative association between lifespan and metabolic rate is in fact an artefact of using resting rather than daily energy expenditure, and of failing to adequately take into account the confounding effects of body size and the lack of phylogenetic independence of species data. When these factors are accounted for, across species of mammals, the ones with higher metabolism also have the largest lifetime expenditures of energy — consistent with the inter-class and intra-specific data. A previous analysis in birds did not yield the same pattern, but this may have been due to a lack of sufficient power in the analysis. Here we present an analysis of a much enlarged data set (>300 species) for metabolic and longevity traits in birds. These data show very similar patterns to those in mammals. Larger individuals have
\end{abstract}

L. J. Furness · J. R. Speakman $(\bowtie)$

Institute of Biological and Environmental Sciences,

University of Aberdeen,

Aberdeen AB24 2TZ Scotland, UK

e-mail: j.speakman@abdn.ac.uk longer lives and lower per-gram resting and daily energy expenditures, hence there is a strong negative relationship between longevity and mass-specific metabolism. This relationship disappears when the confounding effects of body mass and phylogeny are accounted for. Across species of birds, lifetime expenditure of energy per gram of tissue based on both daily and resting energy expenditure is positively related to metabolic intensity, mirroring these statistical relationships in mammals and synergising with the positive associations of metabolism with lifespan within species and between vertebrate classes.

Keywords Birds · Daily energy expenditure - Lifespan · Phylogeny $\cdot$ Rate of living theory $\cdot$ Metabolic rate
Abbreviations
DEE Daily energy expenditure
RMR Resting metabolic rate
ETC Electron transport chain
LEE Lifetime energy expenditure
ATP Adenosine Tri-phosphate
MLSP Maximum lifespan potential
DNA Deoxyribonucleic acid
UCPn Uncoupling protein where $n=1,2$ or 3

\section{Introduction}

This year marks the 100th anniversary of the publication of Rubner's seminal work noting the duration of 
animal lifespan and its relationship to energy expenditure (Rubner 1908). Rubner observed that larger animals live longer and also have lower mass-specific rates of resting metabolic rate (RMR) as measured by indirect calorimetry. Perhaps his key observation, however, was that the product of these two parameters, the lifetime expenditure of energy per gram of tissue, is approximately constant. Tissues appear to burn the same amount of energy during an animal's life, regardless of species. Some animals, like mice (Mus musculus), appear to burn through this allocation rapidly, and consequently die fast, while others, such as elephants (Loxodonta africana), seem to burn energy more slowly and in consequence to live much longer. Rubner's observations were probably very important in the subsequent formulation of the 'rate of living' theory. Published 20 years later by Pearl (1928), this was the first scientific theory of ageing.

The rate of living theory - the idea that animals and humans die sooner if they live faster - received a boost in the 1950s with the advent of the free radical theory of ageing. The free radical theory of ageing was developed by Gerschman et al. (1954) and Harman (1956), who were concerned primarily with the impacts of radiation on tissue damage. Animals exposed to ionising radiation experience various forms of tissue damage and also live much shorter lives than non-irradiated animals. It was argued that these effects provide a model for understanding how natural tissue functions decline with age and ultimately constrain lifespan. These authors argued that numerous endogenous processes generate free radicals (notably oxygen free radicals) and continuously damage macromolecular components of tissue (Gerschman et al. 1954). Probably the most important of these processes is the electron transport chain (ETC), located on the inner membrane of the mitochondria and responsible for generating large quantities of radical oxygen species (Barja 1999). The ETC is also the source of cellular ATP generation that underpins whole-animal metabolic rate. Hence the free radical theory of ageing provides a mechanistic basis for the rate of living theory. In summary, this theory posits that energy metabolism requires consumption of oxygen and generation of ATP via the ETC, which generates radical oxygen species that cause macromolecular damage, the unrepaired accumulation of which ultimately leads to disruption of tissue physiology and death.
This conceptual framework has received substantial support by comparative analyses showing statistical relationships of various additional parameters to observed maximum lifespans of animals. For example, mammals that live longer have lower urinary excretion rates of DNA excision-repair products (8oxoGua and 8-oxodG) (Foksinski et al. 2004), lower oxidative damage to mitochondria (8-oxodG in mitochondrial DNA) (Barja and Herrero 2000; Barja 2002), lower levels of fatty acid desaturation in heart phospholipids, and lower levels of dehydroepiandrosterone (DHEA) in heart phospholipids (Pamplona et al. 1999). Moreover, since Rubner's time, the database of species for which both maximum lifespan and resting metabolism are available has increased enormously, and the fundamental observation that the product of these traits is independent of body size has, until recently, been repeatedly supported (Calder 1984; Prinzinger 2005).

Despite a broad consensus, there are many problems with current understanding of the relationship between metabolic rates and lifespan and the data that support them. We and others have highlighted the main difficulties with the typical "comparative" approach to these issues (Promislow 1991, 1993, 1994; Le Bourg 1996; Speakman et al. 2004; Speakman $2005 a, b)$. One problem is that maximum lifespan data are themselves a poor measure of ageing, principally because they reflect the duration of life of only a single individual. These data in turn depend on how extensively the population of a given species is studied. The more individuals that are measured the greater will be the maximum reported lifespan. Yet data on the size of the monitored population to correct for this effect are seldom available. A second key problem with comparative interspecific analyses of the relationships between various physiological parameters and lifespan is their small sample size and the potentially confounding effect of body size. Because, within vertebrate classes, lifespan is correlated with body size, any other parameter related to body size will also be related to lifespan. Statistical approaches are available to partition the effects of body size and any other trait on lifespan; generally when these are employed the relationships between traits related to energy metabolism, free radical production and lifespan either disappear or are substantially weakened (Speakman 2005a, b; Lambert et al. 2007). A second problem is that the relationship derived by Rubner is based on measures of resting 
energy metabolism; RMR, however, is only a fraction (normally $15-50 \%$ ) of the total daily consumption of energy (Nagy et al. 1999; Speakman 2000). Techniques such as the doubly labelled method are now available to quantify total daily energy expenditure (DEE) (Nagy 1983; Speakman 1998), and when these are used in comparative analyses rather than RMR, the supposed constancy of lifetime mass-specific energy expenditure in relation to body size disappears. In other words, when DEE is substituted for RMR data, our analyses have shown that smaller mammals actually burn more energy per gram of tissue during their lives than larger animals (Speakman 2005a).

The final problem is that statistical relationships generated by inter-specific comparisons seem to be at odds with variation observed within some specieswhich ultimately is a key focus for understanding ageing phenomena. Interspecific comparisons of energy metabolism and lifespan have now been made on several species, and these tend to show that lifespan is actually longer in those individuals that have higher rates of metabolism - both daily and resting (mice: Speakman et al. 2004; dogs: Speakman et al. 2003; hamsters: Oklejewicz and Daan 2002; yeast: Lin et al. 2002; nematodes: van Voorhies and Ward 1999), or that lifespan and metabolic rate are independent (mice: Selman et al. 2007; Drosophila: Hulbert et al. 2004a; Marden et al. 2003; blowflies: Hulbert et al. 2004b; nematodes: van Voorhies 2002; Braeckman et al. 2001). For humans, we have abundant evidence that exercise increases energy metabolism while at the same time decreasing all-risk mortality (Blair et al. 1989, 1996). Finally, a few experimental manipulations have been made of energy expenditure with minimal or non-significant effects on lifespan (Holloszy and Smith 1986; Selman et al. 2008). To add confusion to the picture, however, some manipulations of energy expenditure have supported the negative association between daily energy expenditure and lifespan predicted by the rate-of-living model (Lemon and Barth 1992; Daan et al. 1990; Wolf and Schmid-Hempel 1989).

In our previous analyses of interspecific relationships among energy metabolism, body size and lifespan we focussed primarily on mammals (Speakman 2005b). While an analysis of similar data for birds did not generate exactly the same patterns, this may have been a statistical power issue, since a smaller sample size was involved in that analysis (Speakman 2005b).
Birds show a wide diversity of life history patterns, lifespans and variation in energy metabolism (Holmes and Austad 1995a, b; Holmes et al. 2001) and similar variability in levels of basal (Bennet and Harvey 1985) and daily (Nagy et al. 1999) energy demands. In the current paper we report an analysis of a much larger database on avian energy expenditure and lifespans.

\section{Materials and methods}

Body mass, DEE measured by the doubly labelled water technique, RMR and maximum lifespan potential (MLSP) of birds were collected from the literature. Four main sources were consulted for values of MLSP; Staav (1998), Carey and Judge (2000), the USGS Longevity Records [Patuxent Wildlife Research Center (ND) USGS Longevity Records. Retrieved from http://www.pwrc.usgs.gov/bbl/homepage/longvlst.htm November 2006] and the AnAge database (Human Ageing Genomic Resources 2006; AnAge database. Retrieved from http:/genomics.senescence.info/species/ June 2007). Multiple values for a single species were averaged.

A phylogenetic supertree of all the bird species was created in PDTREE (Garland et al. 1993) based mainly on the avian phylogeny of Sibley and Ahlquist (1990). A phylogenetic tree consists of branches, nodes and tips (or end nodes). The lengths of the branches correspond to evolutionary time, nodes are evolutionary divergences between two or more species and the tips represent either species or genus. Two trait values (such as body mass and DEE) can be entered into each tip using PDTREE. Not all birds had values for all life-history traits (DEE, RMR and MLSP), therefore the tips with missing values were removed from the tree and separate trees were created for each combination of residual life-history traits. Since tips (or species) cannot be regarded as statistically independent, Felsenstein (1985) recommended calculating "phylogenetic contrasts" between each one. The number of un-standardised contrasts is one less than the total number of tips in the tree; standard contrasts (SC) are calculated by dividing each unstandardised contrast by its standard deviation. Hence SC can be regarded as independent values and used in standard statistical procedures (Garland et al. 1993). Phylogenetic independent contrast (PIC) 
Table 1 Sources of phylogenies used to supplement Sibley and Ahlquist (1990)

\begin{tabular}{ll}
\hline Order (Family) & Reference \\
\hline Galliformes & Crowe et al. 2006; Kaiser et al. 2007 \\
Anseriformes & Livezey 1996 \\
Piciformes (Picidae) & Fuchs et al. 2007 \\
Psittaciformes (Psittacidae) & Astuti et al. 2006; Christidis et al. 1991; \\
& Miyaki et al. 1998 \\
Columbiformes (Columbidae) & Johnson et al. 2001; Johnson and Clayton 2000 \\
Gruiformes & Livezey 1998 \\
Ciconiiformes (Scolopacidae) & Thomas et al. 2004; Pereira and Baker 2005 \\
Ciconiiformes (Laridae) & Thomas et al. 2004 \\
Ciconiiformes (Accipitridae) & Lerner and Mindell 2005 \\
Ciconiiformes (Spheniscidae) & Bertelli and Giannini 2005 \\
Ciconiiformes (Procellaridae) & Bertelli and Giannini 2005; Kennedy and Page 2002 \\
Passeriformes (Bombycillidae and Cinclidae) & Cibois and Cracraft 2004; Voelker and Spellman 2004 \\
Passeriformes (Corvidae, Paridae, & Jønsson and Fjeldså 2006; Tieleman et al. 2003 \\
Hirundinidae, Alaudidae, & \\
Passeridae and Fringillidae) & \\
\hline
\end{tabular}

analysis was conducted using the Phenotypic Diversity Analysis Program (PDAP) (Garland et al. 1993).

Sibley and Ahlquist (1990) sometimes did not include all the species for which we have RMR, DEE and MLSP data; to create a tree deep enough to consider each species or genus separately, other avian phylogenies were sought from the literature to supplement their phylogeny (Table 1). Phylogenies using molecular data were preferred; however, morphological phylogenies were also considered. It was not possible to create tips for each species, therefore some tips represent genus. In addition, the phylogeny for the order Trochiliformes was difficult to find; therefore they were placed into hummingbird clades: Mangoes, Coquettes, Brilliants, Mountain Gems, Bees and Emeralds, with a separate tip for the giant hummingbird (Patagona gigas) (taxonomic position based on Altshuler et al. 2004).

\section{Statistics}

Least-squares regressions were performed using MINITAB 13.0. Log RMR, log DEE and log MLSP were regressed against log body mass and residuals of each trait were calculated. Residual values of log DEE and $\log$ RMR were regressed against residual log MLSP to remove the effects of body mass. Residual values were entered into the tips of the phylogenetic trees (Table 1) and contrasts computed. SC of log
RMR and log DEE were regressed against the SC of $\log$ MLSP. To confirm the prediction that lifetime energy expenditure per unit body mass was constant, the lifetime RMR and DEE/gram were calculated (e.g. DEE/body mass * MLSP) and regressed against body mass; these values were also entered into the tips of phylogenetic trees and SC of residual DEE and residual RMR were regressed against the SC of body mass to remove the effect of phylogeny. In addition, lifetime DEE/gram and lifetime RMR/ gram were regressed against metabolic intensity $[\mathrm{DEE}(\mathrm{KJ} / \mathrm{day})$ per gram and RMR (KJ/day) per gram, respectively].

\section{Results}

DEE, RMR and MLSP were all significantly and positively associated with body mass (Fig. 1), corresponding to a significant and negative association between mass-specific DEE and RMR with mass (Fig. 2). Due to shared variation with body mass, MLSP was significantly associated with both massspecific DEE and RMR (Fig. 3). To explore the association between MLSP and both RMR and DEE exclusive of the effects of body mass, we calculated the residuals of $\log$ DEE, $\log$ RMR and log MLSP for the fitted regressions in Fig. 1. Neither residual log DEE nor residual log RMR was significantly related to residual MLSP (Fig. 4). We then calculated the standardised contrasts (SC) of the residual DEE, 

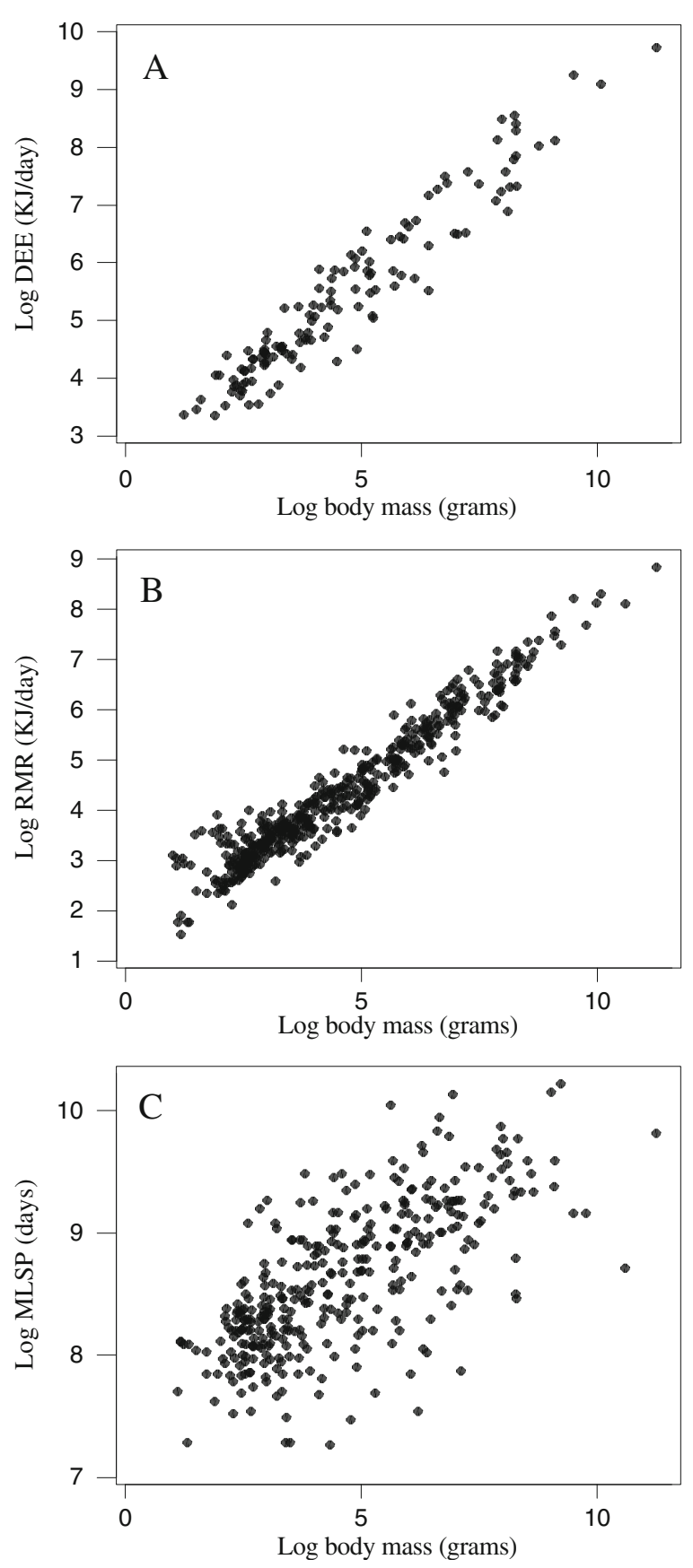

Fig. 1 The effect of $\log$ body mass on $\log$ daily energy expenditure (DEE) (a), log resting metabolic rate (RMR) (b) and $\log$ maximum lifespan potential (MLSP) (c). a $n=130, \log$ $\mathrm{DEE}=2.38+0.658 \log$ body mass, $r^{2}=0.92, F=1,468.57, P<$ 0.001 ; reduced major axis RMA gradient $=0.686$. b $n=459, \log$ $\mathrm{RMR}=1.44+0.643 \log$ body mass, $r^{2}=0.936, \mathrm{~F}=67,20.46, P<$ 0.001 , RMA gradient $=0.665$. c $n=346, \log \mathrm{MLSP}=7.67+0.206$ $\log$ body mass, $r^{2}=0.478, \mathrm{~F}=315.27, P<0.001$
RMR and MLSP using the PDAP programme to remove the effects of phylogeny. Neither the SC of the residual DEE nor the SC of residual RMR was significantly related to the SC of residual MLSP (Fig. 5). Consequently, although DEE and RMR were both highly correlated with MLSP in the raw analysis, when the shared effects of body mass and the effects of phylogenetic dependency were removed, there was no significant relationship.

Rubner (1908) suggested that lifetime energy expenditure per gram was independent of body mass in mammals. In the present study both lifetime DEE/ gram and lifetime RMR/gram were significantly negatively related to body mass (Fig. 6). After
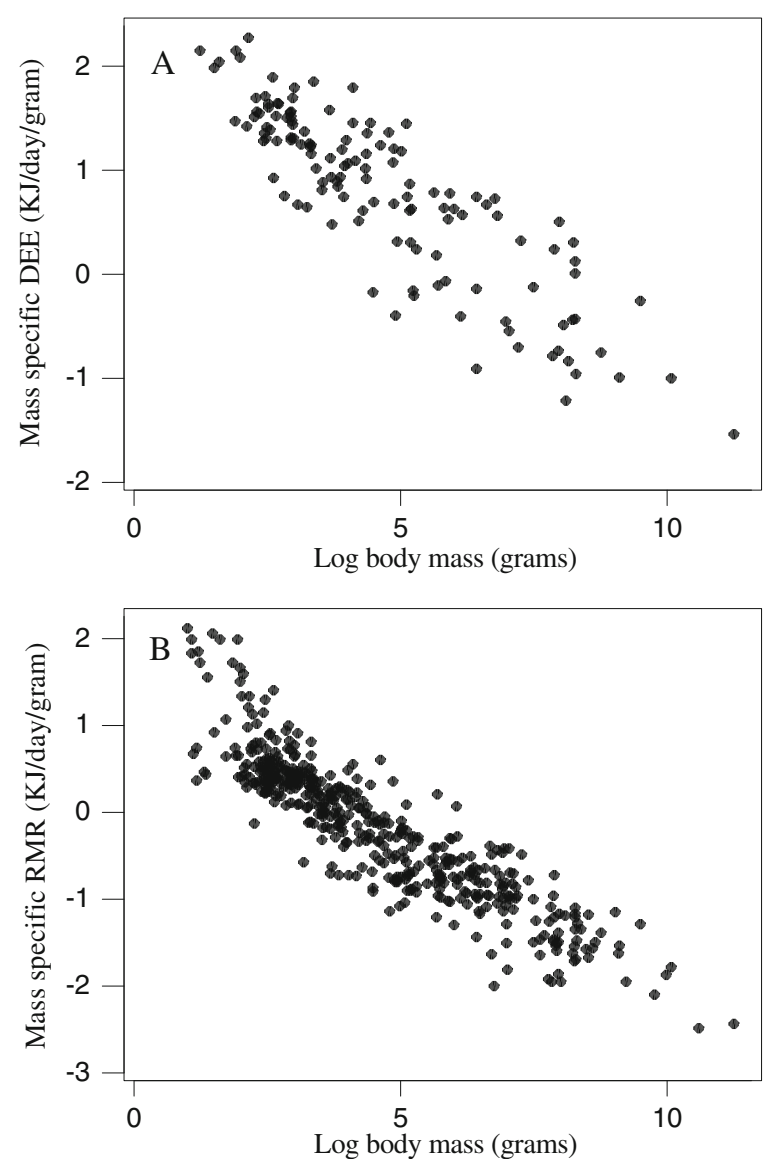

Fig. 2 The effect of $\log$ body mass on mass-specific DEE (a) and RMR (b). a $n=130, \log$ mass-specific $\mathrm{DEE}=2.38-$ $0.342 \log$ body mass, $r^{2}=0.756, F=395.93, P<0.001$, RMA gradient $=-0.297$; b $n=459, \log$ mass-specific $\mathrm{RMR}=1.44-$ $0.357 \log$ body mass, $r^{2}=0.819, F=2068.35, P<0.001$, RMA gradient $=-0.323$ 

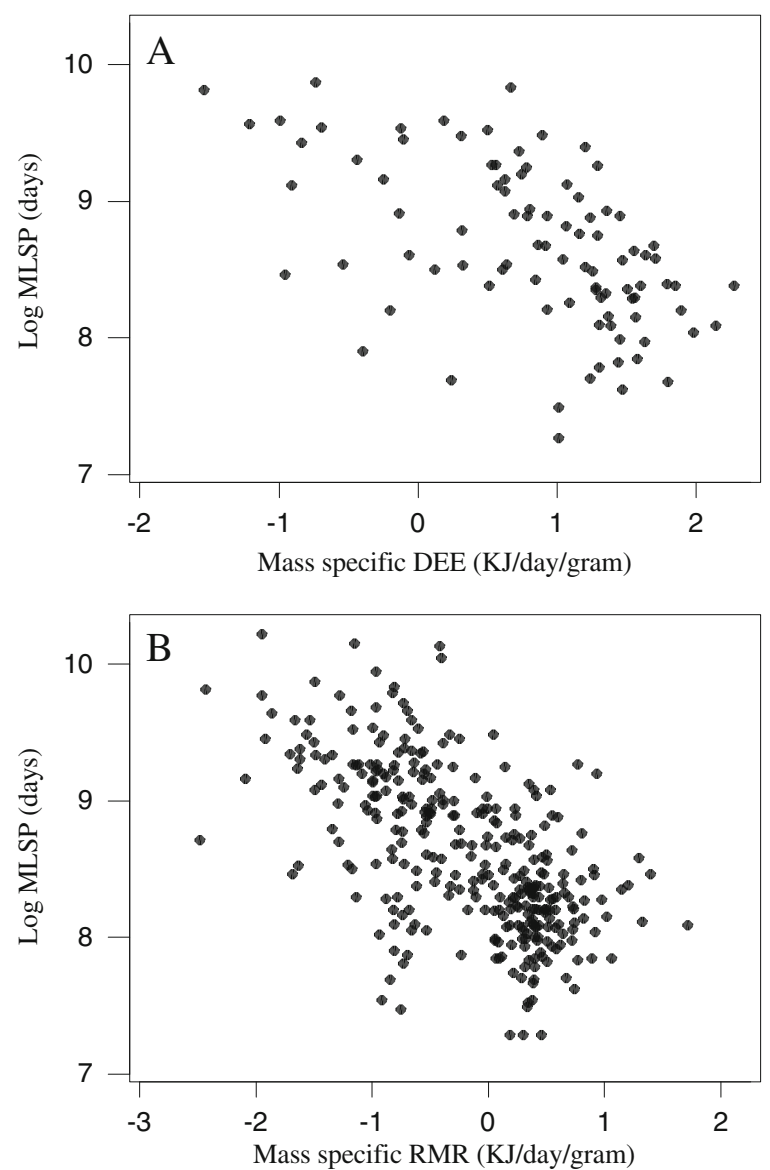

Fig. 3 The effect of mass-specific DEE (a) and RMR (b) on $\log$ MLSP. a $n=92, \log$ MLSP $=8.99-0.388$ mass-specific DEE, $r^{2}=0.296, F=37.84, P<0.001$, RMA gradient $=-0.211$; b $n=321, \log \mathrm{MLSP}=8.52-0.477$ mass-specific RMR, $r^{2}=$ $0.370, F=187.57, P<0.001$, RMA gradient $=-0.290$

removing the effects of phylogeny this effect was still significant and negative (Fig. 7). Lifetime energy expenditure per gram also was dependent on body mass. This means that tissues in smaller birds have much greater energy expenditures over the lifespan of the organism than tissues in larger birds.

Because smaller birds also have greater metabolic intensities, a direct consequence of this negative relationship between body mass and lifetime expenditure of energy is a positive link between metabolic intensity $\left(\mathrm{kJ} \mathrm{day}^{-1}\right.$ gram $^{-1}$ ) and both DEE and RMR and lifetime DEE and RMR per gram (Fig. 8). The explained variability in these relationships are clearly inflated by the inclusion of energy expenditure per gram on both axes and hence should be viewed with caution.

\section{Discussion}

In this study DEE, RMR and MLSP all correlated significantly and positively with avian body mass. The reduced major-axis gradients of the log-converted relationships between both DEE and RMR and body mass $(0.686$ and 0.665$)$ were consistent with allometry as predicted by the surface law (0.67) and observed empirically in other data sets (Heusner 1991; Dodds et al. 2001; White and Seymour 2003). The gradient relating MLSP to mass was the same as that derived previously using a smaller data set (Lindstedt and Calder 1976). In a recent re-emergence of allometric scaling investigations, West et al. (1997) and Gillooly et al. (2001) suggested that most energetics relationships conform to allometric exponents
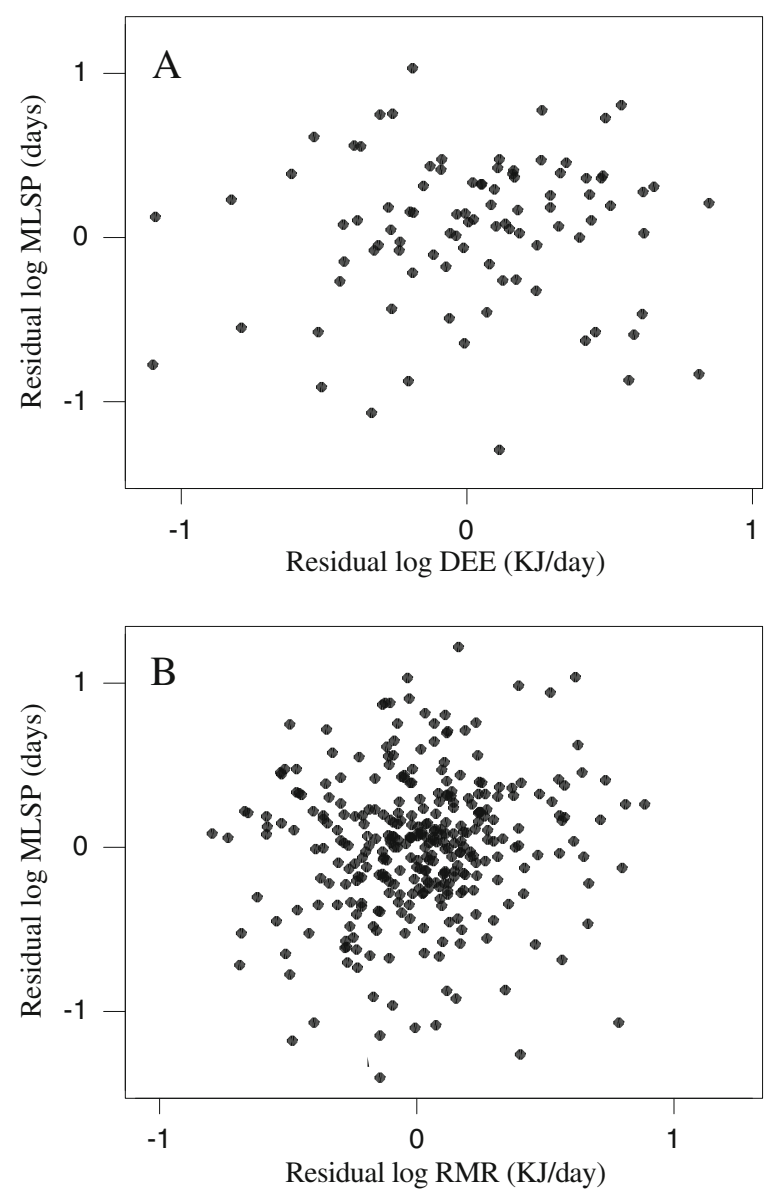

Fig. 4 The effect of residual $\log \operatorname{DEE}$ (a) and residual $\log$ RMR (b) on residual MLSP. a $n=92$, residual $\log \mathrm{MLSP}=$ $0.0414+0.091$ residual log DEE, $r^{2}=0.006, F=0.56, P=0.455$; b $n=321$, residual $\log \mathrm{MLSP}=-0.0005+0.149$ residual $\log$ RMR, $r^{2}=0.011, F=3.53, P=0.061$ 

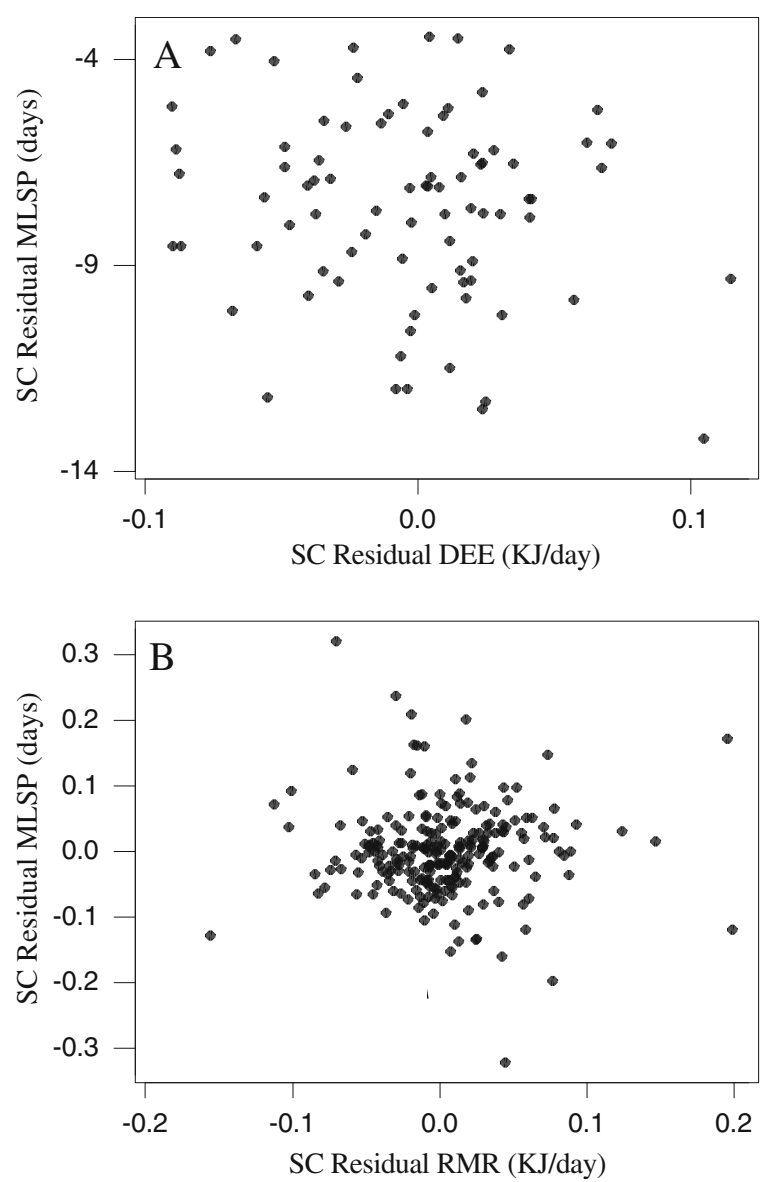

Fig. 5 The effect of the standard contrasts (SC) of residual DEE (a) and SC of residual RMR (b) on the SC of residual MLSP. a $n=83, \mathrm{SC}$ of residual MLSP $=-7.61-8.53 \mathrm{SC}$ of residual DEE, $r^{2}=0.025, F=2.08, P=0.153 ;$ b $n=232$, SC residual $\mathrm{MLSP}=-0.00050-0.000 \mathrm{SC}$ residual $\mathrm{RMR}, r^{2}=$ $0.000, F=0.00, P=0.997$

of around 0.75 , as determined by the rate at which resources are delivered to cells via fractal network systems. However, this proposition has been questioned on both theoretical (Kozłowski and Konarzewski 2004, 2005; Clarke 2006) and empirical grounds (Glazier 2005), and our data similarly did not support 0.75 allometric scaling.

Because both DEE and RMR were positively related to body mass, which was in turn positively related to MLSP, there were also positive relationships between both RMR and DEE and MLSP (Fig. 3). The equivalent relationships using massspecific metabolic rates, on the other hand, were all significant negative relationships (Fig. 2). Previous studies have suggested that the relationship between energy expenditure and lifespan is a consequence of the association of high mass-specific levels of DEE and RMR with high production of mitochondrial reactive oxygen species (ROS). Consistent with this idea, an inverse relationship between ROS production in various tissues and life span has been found in several species (Sohal et al. 1989, 1990; Ku et al. 1993; Barja et al. 1994). In our analysis, however, DEE and RMR were not significantly related to MLSP in birds after the effects of body mass and phylogeny were accounted for. These data are consistent with a previous analysis focussing primarily on mammals (Speakman 2005b), and highlight the critical importance of accounting adequately for size and phylogeny effects in comparative analyses (Promislow 1991; Speakman 2005a).
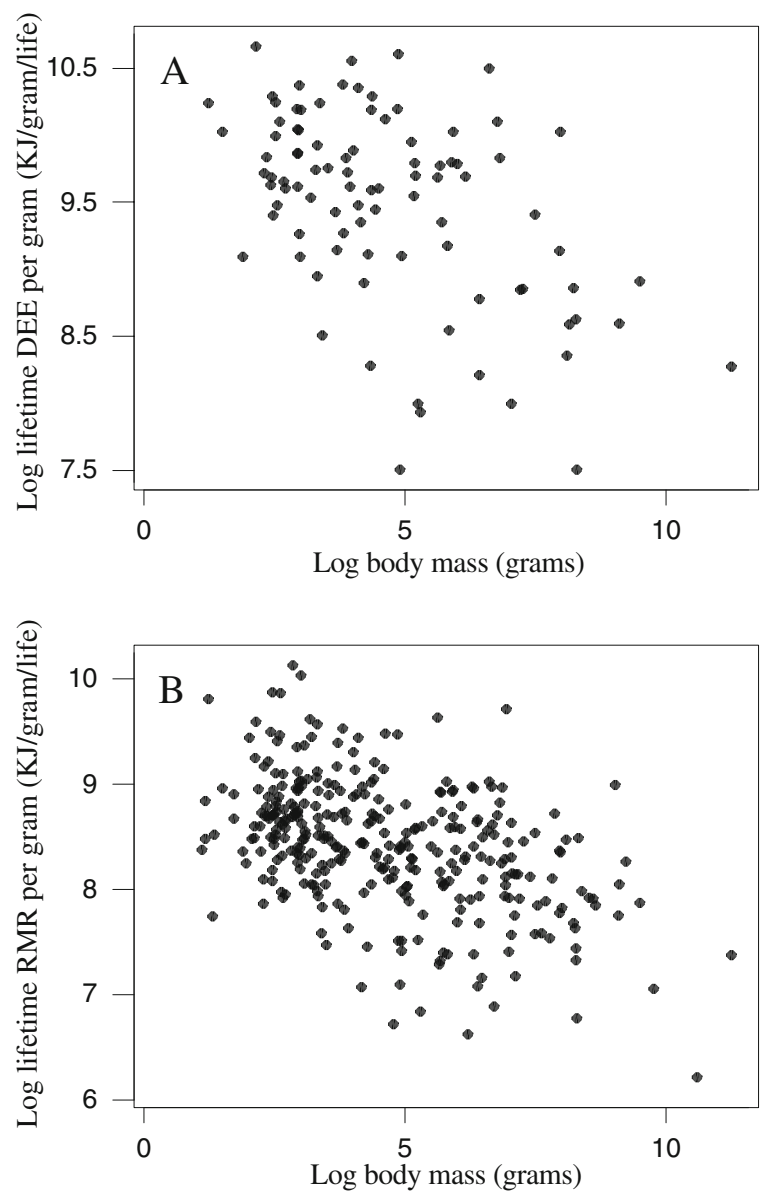

Fig. 6 The effect of log body mass on the log lifetime DEE per gram (a) and log lifetime RMR per gram (b). a $n=92$, lifetime DEE per gram $=10.3-0.171 \log$ body mass, $r^{2}=0.241, F=$ $28.55, P<.001 ; \mathbf{b} n=321$, lifetime RMR per gram $=9.07-$ 0.140 Log body mass, $r^{2}=0.210, F=84.90, P=0.001$ 

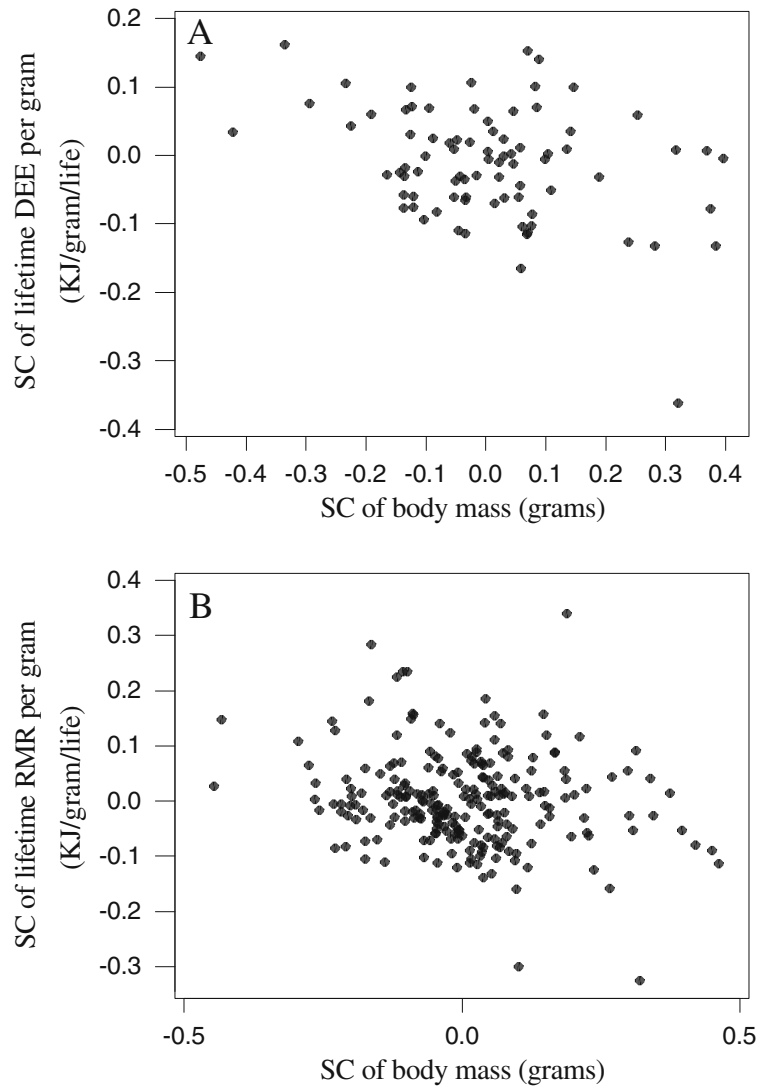

Fig. 7 The effect of the SC of log body mass on the SC of $\log$ lifetime DEE per gram (a) and SC of log lifetime RMR per gram (b). a $n=82, \mathrm{SC}$ of lifetime DEE per gram $=-0.0109-$ $0.185 \mathrm{SC}$ of body mass, $r^{2}=0.139, F=12.88, P=0.001 ; \mathbf{b} n=$ 232, SC of lifetime RMR per gram $=0.00270-0.107 \mathrm{SC}$ of body mass, $r^{2}=0.034, F=8.13, P=0.005$ )

One of the most important insights provided by Rubner was the observation that the product of lifespan and energy metabolism (based on RMR) was independent of body size. In previous work focussing mostly on mammals, we found that when DEE was used in the calculation rather than RMR there was a significant negative association between lifetime expenditure of energy and body mass (Speakman 2005b). In that previous study there was also a trend toward a negative relationship among these variables in birds, but this did not reach statistical significance. In the present study, utilising a much larger database of bird energetics data we found the same result as that previously described in mammals: lifetime expenditure of energy based on DEE was significantly negatively related to body size.

Because there was a negative relationship between lifetime expenditure of energy per gram of tissue and body size, and a similar negative relationship between metabolic intensity (DEE and RMR per gram) and body size, there was consequently a positive association between metabolic intensity and lifetime expenditure of energy (Fig. 8). Species that expend energy at higher rates also spend more energy over their lifetimes per gram of tissue. This result is consistent with observations within species of a positive association between metabolic intensity and longevity (Speakman et al. 2003, 2004; Oklejewicz and Daan 2002; Lin et al. 2002; van Voorhies and Ward 1999).

There are several potential mechanisms that might mediate a positive link between metabolism and lifespan. Two candidate ideas are the membrane pacemaker hypothesis, and the uncoupling to survive hypothesis. The membrane pacemaker hypothesis
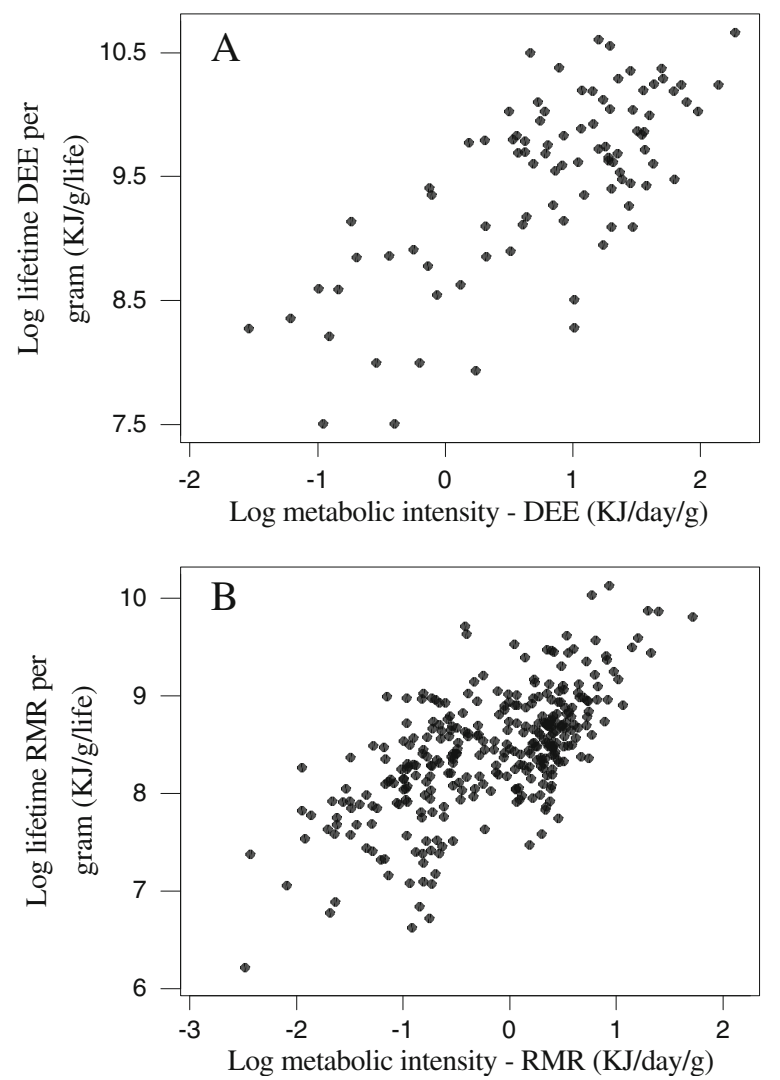

Fig. 8 The effect of metabolic intensity (energy expenditure per gram) on the lifetime energy expenditure per gram in birds for DEE (a) and RMR (b). a $n=92, \log$ lifetime DEE per gram $=8.99+0.612 \log$ DEE per gram, $r^{2}=0.511, F=94.10, P<$ $0.001 ;$ b $n=321$, lifetime RMR per gram $=8.52+0.523 \log$ RMR per gram, $r^{2}=0.415, F=226.26, P<0.001$ 
suggests that interspecific variation in metabolism can be traced to differences in the fatty acid desaturation of membranes (Brand et al. 2002; Brookes et al. 1998; Hulbert 2007; Hulbert and Else 1999, 2005; Hulbert et al. 2002, 2007; Porter et al. 1996). High levels of polyunsaturated fatty acids (PUFAs) are suggested to be linked to higher rates of mass-specific metabolism. However, PUFAs are more prone to oxidative damage, since the double bonds in these compounds form an especially vulnerable target for ROS attack. It has been suggested that species with high membrane PUFA content live correspondingly shorter lives (Pamplona et al. 1999, 2002; Portero-Otin et al. 2001). This association could provide an explanation for the negative relationship we observe between massspecific metabolic rate and lifespan (Fig. 2). We have shown, however, that in both mammals (Speakman 2005a) and birds (present paper) these negative associations are artefacts of the link between both energetic traits and MLSP with body size, as well as the lack of phylogenetic independence in previous analyses. When these confounding effects are removed, the association between energy expenditure and lifespan disappears (Fig. 4).

Similar analyses of the impact of membrane desaturation on lifespan while accounting for phylogeny and body size effects have also shown no association between membrane PUFA content and lifespan (Valencak and Ruf 2007). We recently explored the relationship between metabolic parameters and fatty acid composition of membranes extracted from the livers of mice with variable RMRs (Haggerty et al. 2008). Although we found no link between PUFA and MUFA membrane contents and metabolism, a significant association was detected between residual RMR and the membrane content of the saturated fatty acid 16:0 palmitate. While the cause of this association is not clear, it could potentially contribute to a positive link between metabolism and lifespan, as saturated fatty acids are less prone to ROS-induced damage. It would be interesting to explore the extent to which membrane contents of palmitate are linked either to interspecific variations in RMR or lifespan in birds and mammals.

Mitochondria are responsible for oxidative phosphorylation, in which electrons are passed from reduced substrates (such as NADH or succinate) down a chain of protein complexes on the mitochondrial ETC via a chemiosmotic mechanism to the terminal acceptor oxygen (Mitchell 1976). Electron flow down the chain is coupled to the movement of protons from the mitochondrial matrix to the intermembrane space, creating a protonmotive force driving the passage of protons back into the matrix via ATP-synthase-driven ATP production (Boyer 1997). However, since mitochondria are inefficiently coupled to ATP synthesis, proton leak allows protons to pass back into the matrix without the concomitant production of ATP. This leak occurs via agents called uncoupling proteins (UCPs). This process, which is linearly dependent on membrane potential, may consume up to $20-25 \%$ of resting metabolism (Brand et al. 1994) in various tissues and species, including endotherms and ectotherms (Stuart et al. 2001). It has been suggested that proton leak must be extremely important, since it occurs at the expense of a high proportion of energy production (Brand 2000). Because the action of uncoupling generates heat, adaptive thermogenesis is a possible function of proton leak. This cannot be the principal function, however, since energy is conserved at an almost fixed ratio of resting metabolism in ectotherms as well as endotherms (Rolfe and Brand 1997).

Homologues and possible functions of UCPs have been previously described (Boss et al. 1998; Ricquier and Bouillaud 2000; Brand and Esteves 2005; Sokolova and Sokolov 2005; Echtay 2007). The attenuation of ROS production has received much attention as a likely function of UCPs (Echtay and Brand 2007). In state 3 (active) respiration, the flow of protons across the ETC is unrestricted, producing a lower protonmotive force than in state 4 (resting) respiration (Skulachev 1996). Mild uncoupling produces the same effect, reducing the protonmotive force, increasing the oxidation of electron carriers in the transport chain and reducing the rate at which ROS - particularly superoxide - is generated. In addition, UCP2 and UCP3 knockout mice have been shown to exhibit increased superoxide production compared to that of wild-type mice (Negre-Salvayre et al. 1997; Vidal-Puig et al. 2000), but overexpression of UCP3 did not decrease ROS generation. This suggests that uncoupling over and above that which occurs naturally is unnecessary (Brand et al. 2002). Consistent with this idea is the finding that mice with high metabolic rates have longer lifespans and elevated uncoupling activity via adenine nucleotide translocase and UCP3 (Speakman et al. 2004). 
Given that mild uncoupling generates an inefficient flow of electrons along the ETC, lowering the protonmotive force across the inner mitochondrial membrane and reducing ROS production, and that UCPs are correlated with longer life in mice, uncoupling activity in birds could be the mechanism by which they can achieve high tissue metabolic rates and extended lifetime energy expenditures. In 2001, a UCP homolog was identified in hummingbirds (Vianna et al. 2001), chickens and ducklings (Raimbault et al. 2001), and king penguins (Talbot et al. 2004). Emre et al. (2007) presented evidence that birds have only one UCP and that its function is likely to be varied; one such function could be to decrease ROS production. Consistent with this idea, avian UCP expression has been shown to attenuate ROS production in yeast (Criscuolo et al. 2005).

In conclusion, the associations between DEE, RMR and MLSP and body mass are all significantly positive in birds. After removing potential covariance in body mass and the effects of phylogeny, DEE and RMR were not significantly associated with MLSP; lifetime DEE and RMR per gram, moreover, was significantly and negatively associated with body mass.

Acknowledgements We thank Ted Garland for the PDAP package and his help on the PIC analysis.

\section{References}

Altshuler DL, Dudley R, McGuire JA (2004) Resolution of a paradox: hummingbird flight at high elevation does come without a cost. Proc Natl Acad Sci USA 101:17731-17736

Astuti D, Azuma N, Suzuki H, Higashi S (2006) Phylogenetic relationships within parrots (Psittacidae) inferred from mitochondrial cytochrome- $b$ gene sequences. Zool Sci 23:191-198

Barja G (1999) Mitochondrial oxygen radical generation and leak: sites of production in state 4 and 3 , organ specificity, and relation to aging and longevity. $\mathrm{J}$ Bioener Biomembranes 31:347-366

Barja G (2002) Rate of generation of oxidative stress-related damage and animal longevity. Free Rad Biol Med $33: 1167-1172$

Barja G, Herrero A (2000) Oxidative damage to mitochondrial DNA is inversely related to maximum life span in the heart and brain of mammals. FASEB J 14:312-318

Barja G, Cadenas S, Rojas C, Lopez-Torres M, Perez-Campo R (1994) A decrease of free radical production near critical targets as a cause of maximum longevity in animals. Comp Biochem Physiol Part B Biochem Mol Biol 108: 501-512
Bennett PM, Harvey PH (1985) Active and resting metabolism in birds: allometry, phylogeny and ecology. J Zool 213:327-363

Bertelli S, Giannini NP (2005) A phylogeny of extant penguins (Aves: Sphenisciformes) combining morphology and mitochondrial sequences. Cladistics 21:209-239

Blair SN, Kohl HW 3rd, Paffenbarger RS Jr, Clark DG, Cooper KH, Gibbons LW (1989) Physical fitness and all-cause mortality. A prospective study of healthy men and women. JAMA 262:2395-2401

Blair SN, Kampert JB, Kohl HW 3rd, Barlow CE, Macera CA, Paffenbarger RS Jr, Gibbons LW (1996) Influences of cardiorespiratory fitness and other precursors on cardiovascular disease and all-cause mortality in men and women. JAMA 276:205-210

Boss O, Samec S, Kuhne F, Bijlenga P, AssimacopoulosJeannet F, Seydoux J, Giacobino JP (1998) Uncoupling protein-3 expression in rodent skeletal muscle is modulated by food intake but not by changes in environmental temperature. J Biol Chem 273:5-8

Boyer PD (1997) The ATP synthase - a splendid molecular machine. Annu Rev Biochem 66:717-749

Braeckman BP, Houthoofd K, Vanfleteren JR (2001) Insulinlike signaling, metabolism, stress resistance and aging in Caenorhabditis elegans. Mech Ageing Develop 122:673693

Brand MD (2000) Uncoupling to survive? The role of mitochondrial inefficiency in ageing. Exp Gerontol 35:811-820

Brand MD, Esteves TC (2005) Physiological functions of the mitochondrial uncoupling proteins UCP2 and UCP3. Cell Metab 2:85-93

Brand MD, Chien L-F, Ainscow EK, Rolfe DFS, Porter RK (1994) The causes and functions of mitochondrial proton leak. Biochim Biophys Acta 1187:132-139

Brand MD, Pamplona R, Portero-Otin M, Requena JR, Roebuck SJ, Buckingham JA, Clapham JC, Cadenas S (2002) Oxidative damage and phospholipids fatty acyl composition in skeletal muscle mitochondria from mice underexpressing or overexpressing uncoupling protein 3 . Biochem J 368:597-603

Brookes PS, Buckingham JA, Tenreiro AM, Hulbert AJ, Brand MD (1998) The proton permeability of the inner membrane of liver mitochondria from ectothermic and endothermic vertebrates and from obese rats: correlations with standard metabolic rate and phospholipid fatty acid composition. Comp Biochem Phys B 119:325-334

Calder WA (1984) Size, function, and life history. Harvard University Press, Cambridge

Carey JR, Judge DS (2000) Longevity Records: Life spans of mammals, birds, amphibians, reptiles and fish. Odense University Press, Odense

Christidis L, Scodde R, Shaw DD, Maynes SF (1991) Relationships among the australo-papuan parrots, lorikeets, and cockatoos (Aves: Psittaciformes): protein evidence. Condor 93:302-317

Cibois A, Cracraft J (2004) Assessing the passerine "Tapestry": phylogenetic relationships of the Muscicapoidea inferred from nuclear DNA sequences. Mol Phylogenet Evol 32:264-273

Clarke A (2006) Temperature and the metabolic theory of ecology. Func Ecol 20:405-412 
Criscuolo F, del Mar Gonzalez-Barroso M, Le Maho Y, Ricquier D, Bouillaud F (2005) Avian uncoupling protein expressed in yeast mitochondria prevents endogenous free radical damage. Proc $\mathrm{R}$ Soc 272:803-810

Crowe TM, Bloomer P, Randi E, Lucchini V, Kimball R, Braun E, Groth JG (2006) Supra-generic cladistics of landfowl (Order Galliformes). Acta Zool Sinica 52(supplement): 358-361

Daan S, Deerenberg C, Dijkstra C (1990) Increased daily work precipitates natural death in the kestrel. J Anim Ecol 65:539-544

Dodds PS, Rothman DH, Weitz JS (2001) Re-examination of the "3/4-law" of metabolism. J Theor Biol 209:9-27

Echtay KS (2007) Mitochondrial uncoupling proteins - what is their physiological role? Free Radic Biol Med 43:1351-1371

Echtay KS, Brand MD (2007) 4-Hydroxy-2-nonenal and uncoupling proteins: an approach for regulation of mitochondrial ROS production. Redox Rep 12:26-29

Emre Y, Hurtaud C, Ricquier D, Bouillaud F, Hughes J, Criscuolo F (2007) Avian UCP: the killjoy in the evolution of the mitochondrial uncoupling proteins. J Mol Evol 65:392-402

Felsenstein J (1985) Phylogenies and the comparative method. Am Nat 125:1-15

Foksinski M, Rozalski R, Guz J, Ruszkowska B, Sztukowska P, Piwowarski M, Klungland A, Olinski R (2004) Urinary excretion of DNA repair products correlates with metabolic rates as well as with maximum life spans of different mammalian species. Free Radic Biol Med 37:1449-1454

Fuchs J, Ohlson JI, Ericson PGP, Pasquet E (2007) Synchronous intercontinental splits between assemblages of woodpeckers suggested by molecular data. Zool Scripta 36:11-25

Garland T Jr, Dickerman AW, Janis CM, Jones JA (1993) Phylogenetic analysis of covariance by computer simulation. Syst Biol 42:265-292

Gerschman R, Gilbert DL, Nye SW, Dwyer P, Fenn WO (1954) Oxygen poisoning and $\mathrm{X}$-irradiation: a mechanism in common. Science 119:623-626

Gillooly JF, Brown JH, West GB (2001) Effects of size and temperature on metabolic rate. Science 293:2248-2251

Glazier DS (2005) Beyond the '3/4-power law': variation in the intra- and interspecific scaling of metabolic rate in animals. Biol Rev 80:611-662

Haggerty C, Hoggard N, Brown DS, Clapham JC, Speakman JR (2008) Intra-specific variation in resting metabolic rate in MF1 mice is not associated with membrane lipid desaturation in the liver. Mech Age Develop 129(3):129-137

Harman D (1956) Aging: a theory based on free radical and radiation biology. J Gerontol 11:298-300

Heusner AA (1991) Size and power in mammals. J Exp Biol 160:25-54

Holloszy JO, Smith EK (1986) Longevity of cold exposed rats: a re-evaluation of the rate of living theory. J Appl Physiol 61:1656-1660

Holmes DJ, Austad SN (1995a) The evolution of avian senescence patterns - implications for understanding primary aging processes. Am Zool 35:307-317

Holmes DJ, Austad SN (1995b) Birds as animal-models for the comparative biology of aging - a prospectus. J Gerontol 50:B59-B66
Holmes DJ, Fluckiger R, Austad SN (2001) Comparative biology of aging in birds: an update. Exp Gerontol $36: 869-883$

Hulbert AJ (2007) Membrane fatty acids as pacemakers of animal metabolism. Lipids 42(9):811-819

Hulbert AJ, Else PL (1999) Membranes as possible pacemakers of metabolism. J Theor Biol 199:257-274

Hulbert AJ, Else PL (2005) Membranes and the setting of energy demand. J Exp Biol 208:1593-1599

Hulbert AJ, Faulks S, Buttemer WA, Else PL (2002) Acyl composition of muscle membranes varies with body size in birds. J Exp Biol 205:3561-3569

Hulbert AJ, Clancy DJ, Mair W, Braekman BP, Gems D Partridge L (2004a) Metabolic rate is not reduced by dietary restriction or by lowered insulin/IGF-1 signalling and is not correlated with individual lifespan in Drosophila melanogaster. Exp Gerontol 39:1137-1143

Hulbert AJ, Usher MJ, Wallman JF (2004b) Food consumption and individual lifespan of adults of the blowfly, Calliphora stygia: a test of the 'rate of living' theory of ageing. Exp Gerontol 39:1485-1490

Hulbert AJ, Pamplona R, Buffenstein R, Buttemer WA (2007) Life and death: metabolic rate, membrane composition, and life span of animals. Physiol Rev 87:1175-1213

Johnson KP, Clayton DH (2000) Nuclear and mitochondrial genes contain similar phylogenetic signal for pigeons and doves (Aves: Columbiformes). Mol Biol Evol 14:141-151

Johnson KP, de Kort S, Dinwoodey K, Mateman AC, Cate CT, Lessells CM, Clayton DH (2001) A molecular phylogeny of the dove genera Streptopelia and Columba. Auk 118:874-887

Jønsson KA, Fjeldså J (2006) A phylogenetic supertree of oscine passerine birds (Aves: Passeri). Zool Scripta 35:149-186

Kaiser VB, van Tuinen M, Ellegren H (2007) Insertion events of CR1 retrotransposable elements elucidate the phylogenetic branching Order in Galliform birds. Mol Biol Evol 24:338-347

Kennedy M, Page RDM (2002) Seabird supertrees: combining partial estimates of Procellariiformes phylogeny. Auk 119:88-108

Kozłowski J, Konarzewski M (2004) Is West, Brown and Enquist's model of allometric scaling mathematically correct and biologically relevant? Func Ecol 18:283-289

Kozłowski J, Konarzewski M (2005) West, Brown and Enquist's model of allometric scaling again: the same questions remain. Func Ecol 19:739-743

$\mathrm{Ku}$ HH, Brunk UT, Sohal RS (1993) Relationship between mitochondrial superoxide and hydrogen peroxide production and longevity of mammalian species. Free Radic Biol Med 15:621-627

Lambert AJ, Boysen HM, Buckingham JA, Yang T, Podlutsky A, Austad SN, Kunz TH, Buffenstein R, Brand MD (2007) Low rates of hydrogen peroxide production by isolated heart mitochondria associate with long maximum lifespan in vertebrate homeotherms. Aging Cell 6:607-618

Le Bourg E (1996) Correlational analysis in comparative gerontology: an examination of some problems. Exp Gerontol 31:645-653 
Lemon WC, Barth RH Jr (1992) The effects of feeding rate on reproductive success in the zebra finch, Taeniopygia guttata. Anim Behav 44:851-857

Lerner HR, Mindell DP (2005) Phylogeny of eagles, old world vultures and other Accipitridae based on nuclear and mitochondrial DNA. Mol Phylogenet Evol 37:327-346

Lin SJ, Kaeberlein M, Andalis AA, Sturtz LA, Defossez P-A, Culotta VC, Fink GR, Guarente L (2002) Calorie restriction extends Saccharomyces cerevisiae lifespan by increasing respiration. Nature 418:344-348

Lindstedt SL, Calder WA (1976) Body size and longevity in birds. Condor 78:91-145

Livezey BC (1996) A phylogenetic analysis of geese and swans (Anseriformes: Anserinae) including selected fossil species. Sys Biol 45:415-450

Livezey BC (1998) A phylogenetic analysis of the Gruiformes (Aves) based on morphological characters, with an emphasis on rails (Rallidae). Philos Trans R Soc Lond B Biol Sci 353:2077-2151

Marden JH, Rogina B, Montooth KL, Helfand SL (2003) Conditional tradeoffs between aging and organismal performance of Indy long-lived mutant flies. Proc Natl Acad Sci USA 100:3369-3373

Mitchell P (1976) Vectorial chemistry and the molecular mechanisms of chemiosmotic coupling. Biochem Soc Trans 4:399-430

Miyaki CY, Matioli SR, Burke T, Wajntal A (1998) Parrot evolution and paleogeographical events: mitochondrial DNA evidence. Mol Biol Evol 15:544-551

Nagy KA (1983) Ecological energetics. In: Huey RB, Pianka ER, Schoener TW (eds) Lizard ecology: studies of a model organism. Harvard University Press, Cambridge

Nagy KA, Girard IA, Brown TK (1999) Energetics of free-ranging mammals, reptiles and birds. Ann Rev Nutr 19:247-277

Negre-Salvayre A, Hirtz C, Carrera G, Cazenave G, Troly M, Salvayre R, Penicaud L, Casteilla L (1997) A role for uncoupling protein-2 as a regulator of mitochondrial hydrogen peroxide generation. FASEB J 11:809-815

Oklejewicz M, Daan S (2002) Enhanced longevity in tau mutant Syrian hamsters, Mesocricetus auratus. J Biol Rhyt 17:210-216

Pamplona R, Portero-Otin M, Ruiz C, Gredilla R, Herrero A, Barja G (1999) Double bond content of phospholipids and lipid peroxidation negatively correlate with maximum longevity in the heart of mammals. Mech Age Develop 112:169-183

Pamplona R, Barja G, Portero-Otin M (2002) Membrane fatty acid unsaturation, protection against oxidative stress, and maximum life span - a homeoviscous-longevity adaptation? Ann N Y Acad Sci 959:475-490

Pearl R (1928) The rate of living. University of London Press, UK

Pereira SL, Baker AJ (2005) Multiple gene evidence for parallel evolution and retention of ancestral morphological states in the shanks (Charadriiformes: Scolopacidae). Condor 107:514-526

Porter RK, Hulbert AJ, Brand MD (1996) Allometry of mitochondrial proton leak: influence of membrane surface area and fatty acid composition. Am J Physiol 271: R1550-R1560

Portero-Otin M, Bellmunt MJ, Ruiz MC, Barja G, Pamplona R (2001) Correlation of fatty acid unsaturation of the liver mitochondrial phospholipids classes in mammals to their maximum life span potential. Lipids 36:491-498

Prinzinger R (2005) Programmed ageing: the theory of maximal metabolic scope. EMBO Rep 6:S14-S19

Promislow DEL (1991) Senescence in natural-populations of mammals - a comparative study. Evol 45:1869-1887

Promislow DEL (1993) On size and survival—progress and pitfalls in the allometry of life-span. J Gerontol 48:B115-B123

Promislow DEL (1994) DNA-repair and the evolution of longevity - a critical analysis. J Theor Biol 170:291-300

Raimbault S, Dridi S, Denjean F, Lachuer J, Couplan E, Bouillaud F, Bordas A, Duchamp C, Taouis M, Riquier D (2001) An uncoupling protein homologue putatively involved in facultative muscle thermogenesis in birds. Biochem J 353:441-444

Ricquier D, Bouillaud F (2000) The uncoupling protein homologues: UCP1, UCP2, UCP3, StUCP and AtUCP. Biochem J 345:161-179

Rolfe DFS, Brand MD (1997) The physiological significance of mitochondrial proton leak in animal cells and tissues. Biosci Rep 17:9-16

Rubner M (1908) Das Problem Der Lebensdauer Und Seine Beziehunger Zum Wachstum Und Ernarhnung. Oldenberg, Munich

Selman C, Lingard S, Choudhury AI, Batterham RL, Claret M, Clements M, Ramadani F, Okkenhaug K, Schuster E, Blanc E, Piper MD, Al-Qassab H, Speakman JR, Carmignac D, Robinson ICA, Thornton JM, Gems D, Partridge L, Withers DJ (2007) Evidence for lifespan extension and delayed age-related biomarkers in insulin receptor substrate 1 null mice. FASEB J 22:807-818

Selman C, McLaren JS, Collins AR, Duthie GG, Speakman JR (2008) Experimentally elevating energy expenditure does not increase oxidative stress or reduce lifespan in the shorttailed field vole Microtus agrestis. Proc R Soc B, doi: 10.1098/rspb.2008.0355

Sibley CG, Ahlquist JE (1990) Phylogeny and classification of birds. Yale University Press, New Haven

Skulachev VP (1996) Role of uncoupled and non-coupled oxidations in maintenance of safety low levels of oxygen and its one-electron reductants. Q Rev Biophys 29:169202

Sohal RS, Svensson I, Sohal BH, Brunk UT (1989) Superoxide anion radical production in different species. Mech Ageing Dev 49:129-135

Sohal RS, Svensson I, Brunk UT (1990) Hydrogen peroxide production by liver mitochondria in different species. Mech Ageing Dev 53:209-215

Sokolova IM, Sokolov EP (2005) Evolution of mitochondrial uncoupling proteins: novel invertebrate UCP homologues suggest early evolutionary divergence of the UCP family. FEBS lett 579:313-317

Speakman JR (1998) The history and theory of the doubly labelled water technique. Am J Clin Nutr 68:927S-979S

Speakman JR (2000) The cost of living: field metabolic rates of small mammals. Adv Ecol Res 30:177-297

Speakman JR (2005a) Body size, metabolism and lifespan. J Exp Biol 208:1717-1730

Speakman JR (2005b) Correlations between physiology and lifespan - two widely ignored problems with comparative studies. Aging Cell 4:167-175 
Speakman JR, van Acker A, Harper EJ (2003) Age-related changes in the metabolism and body composition of three dog breeds and their relationship to life expectancy. Aging Cell 2:265-275

Speakman JR, Talbot DA, Selman C, Snart S, McLaren JS, Redman P, Krol E, Jackson DM, Johnson MS, Brand MD (2004) Uncoupled and surviving: individual mice with high metabolism have greater mitochondrial uncoupling and live longer. Aging Cell 3:87-95

Staav R (1998) Longevity list of birds ringed in Europe. EURING news lett 2

Stuart JA, Cadenas S, Jekabsons MB, Roussel D, Brand MD (2001) Mitochondrial proton leak and the uncoupling protein 1 homologues. Biochim Biophys Acta 1504:144-158

Talbot DA, Duchamp C, Rey B, Hanuise N, Rouanet JL, Sibille B, Brand MD (2004) Uncoupling protein and ATP/ ADP carrier increase mitochondrial proton conductance after cold adaptation of king penguins. J Physiol 558:123135

Thomas GH, Wills MA, Székely T (2004) A supertree approach to shorebird phylogeny. BMC Evol Biol 4:28

Tieleman BI, Williams JB, Bloomer P (2003) Adaptation of metabolism and evaporative water loss along an aridity gradient. Proc Biol Sci 270:207-214

Valencak TG, Ruf T (2007) N-3 polyunsaturated fatty acids impair lifespan but have no role for metabolism. Aging Cell 6:15-25
Van Voorhies WA (2002) The influence of metabolic rate on longevity in the nematode Caenorhabditis elegans. Aging Cell 1:91-101

Van Voorhies WA, Ward S (1999) Genetic and environmental conditions that increase longevity in Caenorhabditis elegans decrease metabolic rate. Proc Natl Acad Sci USA 96:11399-11403

Vianna CR, Hagen T, Zhang C-Y, Bachman E, Boss O, Gereben B, Moriscot AS, Lowell BB, Bicudo JEPW, Bianco AC (2001) Cloning and functional characterization of an uncoupling protein homolog in hummingbirds. Physiol Genom 5:137-145

Vidal-Puig AJ, Grujic D, Zhang CY, Hagen T, Boss O, Ido Y, Szczepanik A, Wade J, Mootha V, Cortright R, Muoio DM, Lowell BB (2000) Energy metabolism in uncoupling protein 3 gene knockout mice. J Biol Chem 275:16258-16266

Voelker G, Spellman GM (2004) Nuclear and mitochondrial DNA evidence of polyphyly in the avian superfamily Muscicapoidea. Mol Phylogenet Evol 30:386-394

West GB, Brown JH, Enquist BJ (1997) A general model for the origin of allometric scaling laws in biology. Science 276:122-126

White CR, Seymour RS (2003) Mammalian basal metabolic rate is proportional to body mass ${ }^{2 / 3}$. Proc Natl Acad Sci USA 100:4046-4049

Wolf TJ, Schmid-Hempel P (1989) Extra loads and foraging lifespan in honeybee workers. J Anim Ecol 58:943-954 